\title{
Tau-tubulin kinase 1 and amyloid- $\beta$ peptide induce phosphorylation of collapsin response mediator protein-2 and enhance neurite degeneration in Alzheimer disease mouse models
}

\author{
Seiko Ikezu ${ }^{1^{*}}$, Kaitlin L. Ingraham Dixie ${ }^{1}$, Lacin Koro ${ }^{1}$, Takashi Watanabe ${ }^{2,3}$, Kozo Kaibuchi $^{2,3}$ and
}

Tsuneya Ikezu ${ }^{1,45^{*}}$ (D)

\begin{abstract}
The accumulation of phosphorylated tau protein (pTau) in the entorhinal cortex (EC) is the earliest tau pathology in Alzheimer's disease (AD). Tau tubulin kinase-1 (TTBK1) is a neuron-specific tau kinase and expressed in the EC and hippocampal regions in both human and mouse brains. Here we report that collapsin response mediator protein-2 (CRMP2), a critical mediator of growth cone collapse, is a new downstream target of TTBK1 and is accumulated in the EC region of early stage AD brains. TTBK1 transgenic mice show severe axonal degeneration in the perforant path, which is exacerbated by crossing with Tg2576 mice expressing Swedish familial AD mutant of amyloid precursor protein (APP). TTBK1 mice show accumulation of phosphorylated CRMP2 (pCRMP2), in the EC at 10 months of age, whereas age-matched APP/TTBK1 bigenic mice show PCRMP2 accumulation in both the EC and hippocampal regions. Amyloid- $\beta$ peptide (A $\beta$ ) and TTBK1 suppress the kinetics of microtubule polymerization and TTBK1 reduces the neurite length of primary cultured neurons in Rho kinase-dependent manner in vitro. Silencing of TTBK1 or expression of dominant-negative Rho kinase demonstrates that A $\beta$ induces CRMP2 phosphorylation at threonine 514 in a TTBK1-dependent manner, and TTBK1 enhances A $\beta$-induced CRMP2 phosphorylation in Rho kinase-dependent manner in vitro. Furthermore, TTBK1 expression induces PCRMP2 complex formation with pTau in vitro, which is enhanced upon A stimulation in vitro. Finally, PCRMP2 forms a complex with pTau in the EC tissue of TTBK1 mice in vivo, which is exacerbated in both the EC and hippocampal tissues in APP/TTBK1 mice. These results suggest that TTBK1 and $A \beta$ induce phosphorylation of CRMP2, which may be causative for the neurite degeneration and somal accumulation of pTau in the EC neurons, indicating critical involvement of TTBK1 and PCRMP2 in the early AD pathology.
\end{abstract}

Keywords: Alzheimer's disease, Amyloid- $\beta$ peptide, Amyloid precursor protein, Collapsin response mediator protein-2, Entorhinal cortex, Hippocampus, Microtubule-associated protein tau, Rho kinase, Tau-tubulin kinase 1

\footnotetext{
* Correspondence: sikezu@bu.edu; tikezu@bu.edu

'Departments of Pharmacology and Experimental Therapeutics, Boston

University School of Medicine, Boston, MA, USA

Full list of author information is available at the end of the article
}

(c) The Author(s). 2020 Open Access This article is distributed under the terms of the Creative Commons Attribution 4.0 International License (http://creativecommons.org/licenses/by/4.0/), which permits unrestricted use, distribution, and reproduction in any medium, provided you give appropriate credit to the original author(s) and the source, provide a link to the Creative Commons license, and indicate if changes were made. The Creative Commons Public Domain Dedication waiver (http://creativecommons.org/publicdomain/zero/1.0/) applies to the data made available in this article, unless otherwise stated. 


\section{Introduction}

Alzheimer's disease (AD) is the most prevalent neurodegenerative disorder, characterized by the loss of synapses and neurons, leading to cognitive impairment and dementia. A growing body of evidence reveals that neurons affected in AD display "a dying-back pattern", in which neurons start degenerating at the synapse or axon terminal then gradually die back toward cell-soma. Previous neuroimaging studies report significant axonal degeneration in the perforant path (PP) region in patients with mild cognitive impairment as determined by using magnetic resonance imaging and diffuse tensor imaging $[1,2]$. The PP represents important axonal tracts that connect neurons in the entorhinal cortex (EC) to the dentate gyrus (DG) and other areas of the hippocampus [3]. This pathway is essential to many forms of memory, including spatial memory [4], which is significantly impaired in AD patients. The axons of the PP arise primarily from layer II neurons in the EC where somatic accumulation of hyperphosphorylated tau protein is detected in the early stage of AD. This dying-back axonal degeneration in the PP and accumulation of phosphorylated tau protein in the EC neuron are the critical initial events in AD pathophysiology in the context of the initiation and propagation of tau pathology, however, its mechanisms remain elusive.

We have previously shown that tau-tubulin kinase 1 (TTBK1), a brain-specific tau kinase, is specifically enriched in the PP of TTBK1 transgenic mice harboring BAC containing the human TTBK1 genome [5], followed by the EC, pyramidal layer of Cornu Ammonis (CA)1-3 fields and the granular layer of dentate gyrus in the hippocampal fields [6, 7]. A recent independent human study has confirmed that TTBK1 mRNA is highly expressed in the EC, subiculum, CA field, and DG in both AD and non-demented cases [8]. TTBK1 directly phosphorylates tau protein at Y197, S198, S199, S202 and S422 in vitro, and also enhances tau phosphorylation via unique activation of cyclin-dependent kinase $5(\mathrm{Cdk} 5)$ upon dissociation of G-actin from Cdk5 in vitro and in vivo [5-7]. Further, TTBK1 protein expression is significantly upregulated in the frontal neocortical region of the AD brain [7], and certain genetic variations of the TTBK1 gene are associated with late-onset $\mathrm{AD}$ in two cohorts of Chinese and Spanish populations $[9,10]$. TTBK1 transgenic mice harboring the entire genomic sequence of human TTBK1 show accumulation of hyperphosphorylated tau in the cortex (including the EC) and hippocampal formation when crossed with P301L tau mice (JNPL3) [5]. Moreover, our recent study has shown that crossing P301L tau mice with TTBK1 transgenic mice accelerates axonal degeneration of spinal motoneurons, and silencing TTBK1 partially blocks lipopolysaccharide-stimulated microgliainduced neurite degeneration [11]. While multiple tau kinases including GSK3 $\beta$, CDK5, or casein kinase 2 and tau itself have been reported to contribute to axonal degeneration in AD especially through axonal transport deficit [12], no kinase except TTBK1 is specifically expressed in the EC and PP where early AD pathology evolves. Thus, we hypothesize that TTBK1 may play a critical role in axonal degeneration of the PP through phosphorylation and aggregation of tau in AD.

In this study, we investigated the role of TTBK1 in AD pathology using an APP/ TTBK1 double transgenic mouse model. We specifically focused on the synergistic effect of TTBK1 and APP on phosphorylation of collapsing response mediator protein-2 (pCRMP2), an anterograde cargo transporter of tubulin dimers and a critical mediator of growth cone collapse. Phosphorylation of CRMP2 at T514 by GSK3B after its phosphorylation at S522 by CDK5 is critical for neuronal cell polarity [13]. Since pCRMP2 is also found in the neurofibrillary tangles [14], we examined the mechanism of axonal degeneration of the PP and accumulation of phosphorylated tau protein and PCRMP2 in the EC and hippocampal region in $\mathrm{AD}$ mouse models. AD patients' brain samples were also tested to find the association between pathology measured on the Braak scale and TTBK1 and pCRMP2 expression in the EC and hippocampal region. Here we report that TTBK1 and CRMP2 may elucidate the relationship between $A \beta$ deposition and ECspecific accumulation of phosphorylated tau protein, and neurite degeneration in early stage $\mathrm{AD}$.

\section{Materials and methods}

\section{Transgenic animal models}

All experimental procedures using animals were approved by the Institutional Animal Care and Use Committee at Boston University School of Medicine. Tg2576 (APP) mice expressing the Swedish mutation of human APP (isoform 695) were obtained from Drs. G. Carlson and $\mathrm{K}$. Ashe and maintained on a B6/129 background [15]. TTBK1 transgenic mice (Line 141) harboring the human TTBK1 genomic fragment were maintained on a B6/129 background as described previously [5, 7, 11]. Tg2576 mice were crossed with TTBK1 mice to generate APP, TTBK1, APP/TTBK1 and non-transgenic (non-Tg) littermates and tested at 10-11 months of age.

\section{Immunofluorescence}

Age-matched APP, TTBK1, APP/TTBK1 and non-Tg littermates (10-11 months of age) were deeply anesthetized with isoflurane inhalation and transcardially perfused with $4 \%$ paraformaldehyde in PBS (Sigma-Aldrich, St. Louis, MO). Brain tissues were cryoprotected by successive $24 \mathrm{~h}$ immersions in 15 and 30\% sucrose in PBS, mounted in OCT compound. The tissue blocks were serially cryosectioned at $10 \mu \mathrm{m}$-thickness on coronal planes through regions of interest including the entorhinal cortex and hippocampal formations using a microtome cryostat (Microm HM525, Thermo 
Fisher Scientific), and mounted on Superfrost ${ }^{\mathrm{TM}}$ Plus slides (Thermo Fisher Scientific). The tissue sections were subjected to immunofluorescence using pT514 CRMP2 rabbit polyclonal antibody (1:2000 dilution, generated by Kaibuchi laboratory), followed by Alexa Fluor 488 (Life technologies, Grand Island, NY) secondary antibody and Dapi (1:2000 dilution, Thermo Fisher Scientific). Immunostained images were captured using an inverted fluorescence microscope attached to a monochromatic CCD camera (TE-2000 U, Nikon Instruments, Melville, NY) and fluorescence intensity was quantified with Image software (NIH).

\section{Retrograde tracing by hippocampal injection of Dil}

Paraformaldehyde-fixed mouse brain tissues were dissected in a coronal plane at $-3.40 \mathrm{~mm}$ (AP) posterior to bregma. The blocks including entorhinal cortex were post-fixed for at least 2 days in $4 \%$ paraformaldehyde in PBS. After postfixation, $0.5 \mu \mathrm{l}$ of $\mathrm{DiI}\left(1,1^{\prime}\right.$-Dioctadecyl-3,3,3',3'-Tetramethylindocarbocyanine Perchlorate, $2.5 \mathrm{mg} / \mathrm{mL}$ in dimethyl sulfoxide, Thermo Fisher Scientific) was injected into the stratum moleculare of the dentate gyrus of the hippocampal field using a motorized microinjector (Stoelting, Wood Dale, IL) and a $10-\mu \mathrm{L}$, gas-tight micro syringe (Hamilton, Reno, NV), which was set on the stereotaxic platform (David Kopf Instruments, Tujunga, CA). DiI injected tissues were stored in PBS and $0.2 \%$ sodium azide solution at $37^{\circ} \mathrm{C}$ for 4 weeks in the darkness. Tissue blocks were then embedded in 3\% agarose gel and cut in the sagittal plane at $30 \mu \mathrm{m}$-thickness by the vibratome (Leica, Buffalo Grove, IL), counter-stained with Dapi (1:2000 dilution, $20 \mathrm{~min}$ ) and subjected to fluorescence microscopic imaging as described. DiI fluorescence intensity was quantified with ImageJ software (NIH). The ML coordinate of the MEC region for the quantification is $+2.84-+2.99(150 \mu \mathrm{m}$ total thickness) using 6 consecutive sections.

\section{Plasmids and TTBK1 siRNA}

DNA plasmids encoding HA-tagged human full length TTBK1 (HA-TTBK1) in pcDNA3.1+ vector was tested as previously described [6]. Myc-tagged human wild-type (WT) and mutant CRMP2 (S522A, T555A) in a pCAGGS vector [16], and dominant negative RhoK [pEF-BOS-Myc$\mathrm{RB} / \mathrm{PH}$ (TT)] vector [17] were as previously described. TTBK1 shRNA sequence (clone 19; 5'-GCTCTTAAGG ACGAAACCAACATGAGTGG-3') was subcloned into pVL-EGFP-Puro and pSuper shRNA vectors.

\section{Tissue and cell culture}

Human neuroblastoma cell line SH-SY5Y that stably expressed wild type Tau (2N4R, 1-411; kindly provided by Roger M. Nitsch) [18, 19] or human embryonic kidney 293 cell line (HEK293) were maintained in a 5\% CO2 humid atmosphere at $37^{\circ} \mathrm{C}$ in Dulbecco's modified eagle medium/Ham's F12 nutrient mixture (DMEM/F12) with
$10 \%$ fetal bovine serum, $10 \mathrm{U} / \mathrm{ml}$ penicillin, and $10 \mu \mathrm{g} / \mathrm{ml}$ streptomycin (all from Life technologies) as described [6]. Primary cultured murine cortical neurons were prepared from E16 embryonic CD-1 mouse brains and plated on poly-D-lysine-coated coverslips in 24-well plates (Thermo Fisher Scientific Inc., Waltham, MA) as described [11].

\section{DNA plasmid transfection and amyloid- $\beta$ treatment}

HEK 293 cells $\left(2 \times 10^{6}\right.$ cells / 6 well plate) were transfected with $2 \mu \mathrm{g}$ of each plasmid (CRMP2 wild type, CRMP2 S522A mutant, or CRMP2 T555A mutant) or $20 \mathrm{pmol}$ of siRNA with $10 \mu \mathrm{l}$ Lipofectamine 2000 (Thermo Fisher Scientific). Twenty-four $h$ after the transfection, cells were incubated with 0,3 , or $10 \mu \mathrm{M}$ of freshly prepared human synthetic amyloid- $\beta$ peptide $1-42$ (A $\beta 42$, Life technologies) for $24 \mathrm{~h}$ as described $[20,21]$. Primary murine cortical neurons $\left(1 \times 10^{5}\right.$ cells $/ 24$ well plate) were cultured as previously described [11] and transfected with $0.5 \mu \mathrm{g}$ of each plasmid [TTBK1, GFP and/or dominant negative RhoK] with $4 \mu \mathrm{L}$ of Lipofectamine 2000 (Life technologies).

\section{Analysis of neurite length and branches}

Three days after the transfection, murine cortical neuronal cells were fixed with $4 \%$ paraformaldehyde in PBS solution, and GFP signal was captured by monochromatic CCD camera. NeuronJ plug-in was used on ImageJ $(\mathrm{NIH}$, Bethesda, MD) to measure the length of axons and number of dendrites emanating from the cell soma [22].

\section{Immunoblotting}

Whole cell lysates were prepared in RIPA lysis buffer containing 1\% NP-40, 0.5\% sodium deoxycholate and $0.1 \%$ SDS in the presence of $1 \mathrm{mM}$ PMSF, $1 \mathrm{mM} \mathrm{NaF}$ and 1 $\mathrm{mM} \mathrm{Na} \mathrm{VO}_{4}$ after centrifugation at $20,817 \times g$ for $30 \mathrm{~min}$ at $4{ }^{\circ} \mathrm{C}$. Twenty $\mu$ g protein/sample were subjected to $4-$ 15\% SDS-PAGE (Bio-Rad laboratories, Hercules, CA) and immunoblotted for anti-phosho-Thr514 CRMP2 (pT514CRMP2, rabbit polyclonal, 1:1000) [13], anti-total CRMP2 mouse monoclonal (C4G mAb, 1:500, IBL. Inc., Minneapolis, MN) [23], and anti-TTBK1 mouse monoclonal (20 $\mu \mathrm{g} / \mathrm{ml}$, clone F287-1.1-1E9) [7].

End-binding protein 3 (EB3)-GFP live confocal microscopy SH-SY5Y cells plated on collagen type I-coated dishes 35 mm MatTek dishes (MatTek Corp, Ashland, MA) at $2 \times 10^{5}$ cells / dish and incubated with $10 \mu \mathrm{M}$ all-trans-retinoic acid (Sigma) for 6 days in standard culture medium containing $1 \%$ FBS and then for an additional 2 days in serum free medium containing $2 \mathrm{nM}$ brain-derived neurotrophic factor (BDNF, Sigma) as previously described $[6,24]$. The cells were co-transfected with $0.5 \mu \mathrm{g}$ of each plasmid (EB3-GFP and TTBK1 or EB3-GFP and pcDNA3.1 ${ }^{+}$) and pretreated with $10 \mu \mathrm{m}$ freshly prepared A $\beta 42$ oligomer or vehicle as described $[21,25]$. The live imaging of comet movement of 
EB3-GFP homodimer was captured $24 \mathrm{~h}$ after the transfection using following setting: $100 \times$ oil objective $(\mathrm{NA}=1.45)$, $488 \mathrm{~nm}$ excitation (100-300 ms exposure/frame, single plane), $0.53 \mathrm{fps}$ for 40 frames, using the Nikon TE-2000 U inverted fluorescent microscope (Nikon Instruments, Melville, NY) output port and cooled charge-coupled device camera (Coolsnap HQ, Roper Scientific, Duluth, GA) as described $[21,25,26]$.

\section{Immunoprecipitation assay}

Recombinant Myc-tagged human CRMP2 was transiently expressed in SH-SY5Y cells stably expressing P301L human tau (2N4R) [19], and treated with $10 \mu \mathrm{M}$ of freshly prepared amyloid- $\beta$ peptide $1-42$ (A $\beta 42$, Life technologies) for $24 \mathrm{~h}$. Forty eight $\mathrm{h}$ after the DNA plasmid transfection, cell lysates were prepared using RIPA buffer and incubated over night at $4{ }^{\circ} \mathrm{C}$ with anti-Myc rabbit polyclonal (1:150 dilution, Covance Inc., Dedham, MA) or anti-phosho-T514 CRMP2 rabbit polyclonal antibody (1: 100 dilution, generated by Kaibuchi Laboratory). The mixture was then incubated with $20 \mu \mathrm{L}$ of $50 \%$ protein $\mathrm{G}$ plus-agarose (Sigma-Aldrich, St. Louis, MO) for $4 \mathrm{~h}$ at $4{ }^{\circ} \mathrm{C}$ with gentle rocking. After three washes in the icecold RIPA buffer, the immunoprecipitates were separated by 4-10\% SDS-PAGE (Bio-Rad) and immunoblotted for phosphorylated tau (AT8 mouse monoclonal, 1:500 dilution, Thermo Fisher Scientific), non-phosphorylated tau specific to Ser 195, Ser 198, Ser 199 and Ser 202 (Tau-1 mouse monoclonal, 1:200 dilution, Millipore, Temecula, California) [27], total tau (Tau46 mouse monoclonal, 1: 500 dilution, Abcam, Cambridge, MA), or total CRMP2 (clone C4G, mouse monoclonal, 1:500 dilution, IBL America, Minneapolis, MN).

For in vivo tau and CRMP2 binding assay, the cortical and hippocampal tissues were dissected from mouse brains and homogenized in ice-cold RIPA buffer containing protease and phosphatase inhibitor cocktails (Roche, Cambridge, MA), followed by centrifugation at 20,817 $\times g$ for $30 \mathrm{~min}$ at $4{ }^{\circ} \mathrm{C}$. The protein concentration of the protein extract supernatant was determined using a BCA assay kit (Thermo Fisher Scientific). pCRMP2 was immunoprecipitated from $2 \mathrm{mg}$ of protein extracts by antiphosho-T514 CRMP2 rabbit polyclonal antibody (1:100 dilution) and protein A/G sepharose (Santa Cruz Biotech, Dallas, TX), and the immunoprecipitants were blotted for phosphorylated tau (AT8) and total tau (Tau46).

\section{Human brain specimens}

The entorhinal cortex and hippocampus brain tissue samples were obtained from the Boston University Alzheimer's Disease Center (BUADC) Brain Bank and also the Harvard Brain Tissue Resource Center. Post-mortem interval was $<24 \mathrm{~h}$, if possible, with the brain samples from the BUADC Brain Bank. The criteria for AD were based on the presence of amyloid- $\beta$ neuritic plaques and neurofibrillary tangles according to the NIA-Reagan criteria for intermediate and high likelihood AD and the recent NIA Alzheimer Association's guidelines [28, 29]. The NIA-Reagan criteria take into account both the Braak staging for neurofibrillary tangles [30,31] and the overall density of neuritic plaques based on CERAD criteria [32]. The hippocampal and entorhinal cortex tissues were obtained from Braak stage I-IV patients. The demographic information of all of the patients from BUADC Brain Bank used for this study are described in Table 1. Brain tissues were paraffin embedded, then cut at $8 \mu \mathrm{m}$ by the microtome by Boston University Pathology Laboratory Service Core. The paraffin sections were mounted on Superfrost ${ }^{\text {тм }}$ Plus slides (Thermo Fisher Scientific).

\section{Immunohistochemistry (human brain sections)}

Deparaffinized sections were incubated with proteinase $\mathrm{K}$ $(20 \mu \mathrm{g} / \mathrm{ml})$ in Tris-EDTA- $\mathrm{CaCl}_{2}$ buffer at $37^{\circ} \mathrm{C}$ in humidified chamber at room temperature for $10 \mathrm{~min}$ each, rinsed in tris-buffered saline (TBS) with $0.025 \%$ Triton X-100 and permeabilized with $0.1 \%$ Triton-X 100 in TBS for 10 min. After further washing with TBS, sections were incubated with blocking buffer (10\% horse serum with $1 \%$ bovine serum albumin in TBS) for $2 \mathrm{~h}$ at room temperature, then incubated with following primary antibodies at $4{ }^{\circ} \mathrm{C}$ for $48 \mathrm{~h}$ : TTBK1 mouse monoclonal (1:20, clone 1E9 generated by Ikezu laboratory) [7], 3F4 anti-pCRMP2 mouse monoclonal (1:100, ILB America), which detects pT509/ pS518/pS522 [23] and pT514-CRMP2 rabbit polyclonal (1:2000, custom affinity-purified antibody developed at Kaibuchi laboratory) [13]. Endogenous peroxidase activity was inhibited with $0.3 \%$ hydrogen peroxide (Sigma-Aldrich) incubation. Sections were then incubated with

Table 1 Immunohistochemistry of layer II entorhinal cortical and CA1 hippocampal regions of human brain tissues for TTBK1 and $\mathrm{PCRMP2}$

\begin{tabular}{|c|c|c|c|c|c|c|c|}
\hline \multirow{2}{*}{$\begin{array}{l}\text { Patient } \\
\text { ID }\end{array}$} & \multirow{2}{*}{$\begin{array}{l}\text { Age } \\
\text { (YR) }\end{array}$} & \multirow{2}{*}{$\begin{array}{l}\text { Braak } \\
\text { Stage }\end{array}$} & \multirow[t]{2}{*}{ Sex } & \multicolumn{2}{|c|}{ ТТВК1 } & \multicolumn{2}{|c|}{ pCRMP2 } \\
\hline & & & & EC II & CA1 & EC ॥ & CA1 \\
\hline 1 & 89 & 1 & M & 0 & 0 & + & +++ \\
\hline 2 & 87 & I & $\mathrm{F}$ & 1 & 1 & - & - \\
\hline 3 & 92 & I & $\mathrm{F}$ & 1 & 1 & - & - \\
\hline 4 & 90 & $\|$ & M & 2 & 2 & ++ & ++ \\
\hline 5 & 84 & $\|$ & M & 0 & 0 & ++ & +++ \\
\hline 6 & 96 & ॥ & $\mathrm{F}$ & 1 & 1 & - & - \\
\hline 7 & 93 & III & M & 2 & 1 & ++ & +++ \\
\hline 8 & 93 & III & $\mathrm{F}$ & 1 & 2 & + & +++ \\
\hline 9 & 92 & III & $\mathrm{F}$ & 1 & 1 & +++ & + \\
\hline 10 & 92 & IV & M & 1 & 1 & +++ & +++ \\
\hline 11 & 96 & IV & F & 1 & 1 & ++ & +++ \\
\hline 12 & 81 & IV & $M$ & 3 & 3 & +++ & +++ \\
\hline
\end{tabular}


secondary anti-mouse antibody (Immpress-HRP antimouse IgG (peroxidase polymer detection kit, Vector Laboratories, Burlingame, CA) for $30 \mathrm{~min}$. The 3,3'-Diaminobenzidine (DAB; Vector Laboratories) staining was used as a chromogen, and hematoxylin was used for counterstaining. Immunostained images were captured using a Nikon Eclipse E600 microscope and a color charge-coupled device camera (Nikon Instruments, Melville, NY). The number of 3F4 $\left(\right.$ pCRMP2 $^{+}$cells were quantified using 10 sections/donor in the EC II region, and ranked as - (< average 0.5 cell/field $)$, + (average $0.5-1$ cell/field), ++ (average 1-2 cells/field), +++ (average $2-3$ celsl/field) and ++++ (average $>3$ cells/field).

DAB intensity of TTBK1 in EC and CA1 regions was measured according to the previous methods [33]. Briefly, captured images were saved as 24-bit RGB TIFF format and converted to CMYK TIFF format by adobe Photoshop CS5 software. Intensity in the Y channel of individual cells was measured as $\mathrm{DAB}^{+}$immunoreactive signals by image J software. Signal/Noise $(\mathrm{S} / \mathrm{N})$ ratio of at least 50 cells were averaged and ranked as $0(\leq 0.5 \mathrm{~S} /$ $\mathrm{N}), 1(0.5<\mathrm{S} / N \leq 1), 2(1<\mathrm{S} / N \leq 1.5), 3(1.5<\mathrm{S} / N \leq 2)$, and $4(>2 \mathrm{~S} / \mathrm{N})$. Representative transformation from original RGB images to Y channel images in CMYK format was shown in Additional file 1: Figure S1.

\section{Results}

TTBK1 and phosphorylated CRMP2 are highly expressed in the $\mathrm{EC}$ and hippocampal region in $\mathrm{AD}$ brains

In order to investigate the involvement of TTBK1 in AD pathology at the early stage, we assessed whether the expression of TTBK1 in the EC and hippocampal region is correlated with the Braak stage of AD using human brain specimens (Table 1). Immunohistochemistry using TTBK1 monoclonal antibody (clone IE9) revealed that TTBK1 is expressed highly in the cell soma and dendrites in the EC and hippocampal neurons including the DG, subiculum and CA1-3 field (Fig. 1a). Intensity measurements of TTBK1 immunoreactivity in the pyramidal cell soma of layer II EC neurons and CA1 showed consistent expression of TTBK1 from Braak I to IV stages (Table 1). In addition, $\mathrm{TTBK} 1^{+}$neurons were partially co-localized with $\mathrm{AT}^{+}$specific to $\mathrm{pS} 202 / \mathrm{pS} 205$ phosphorylated tau

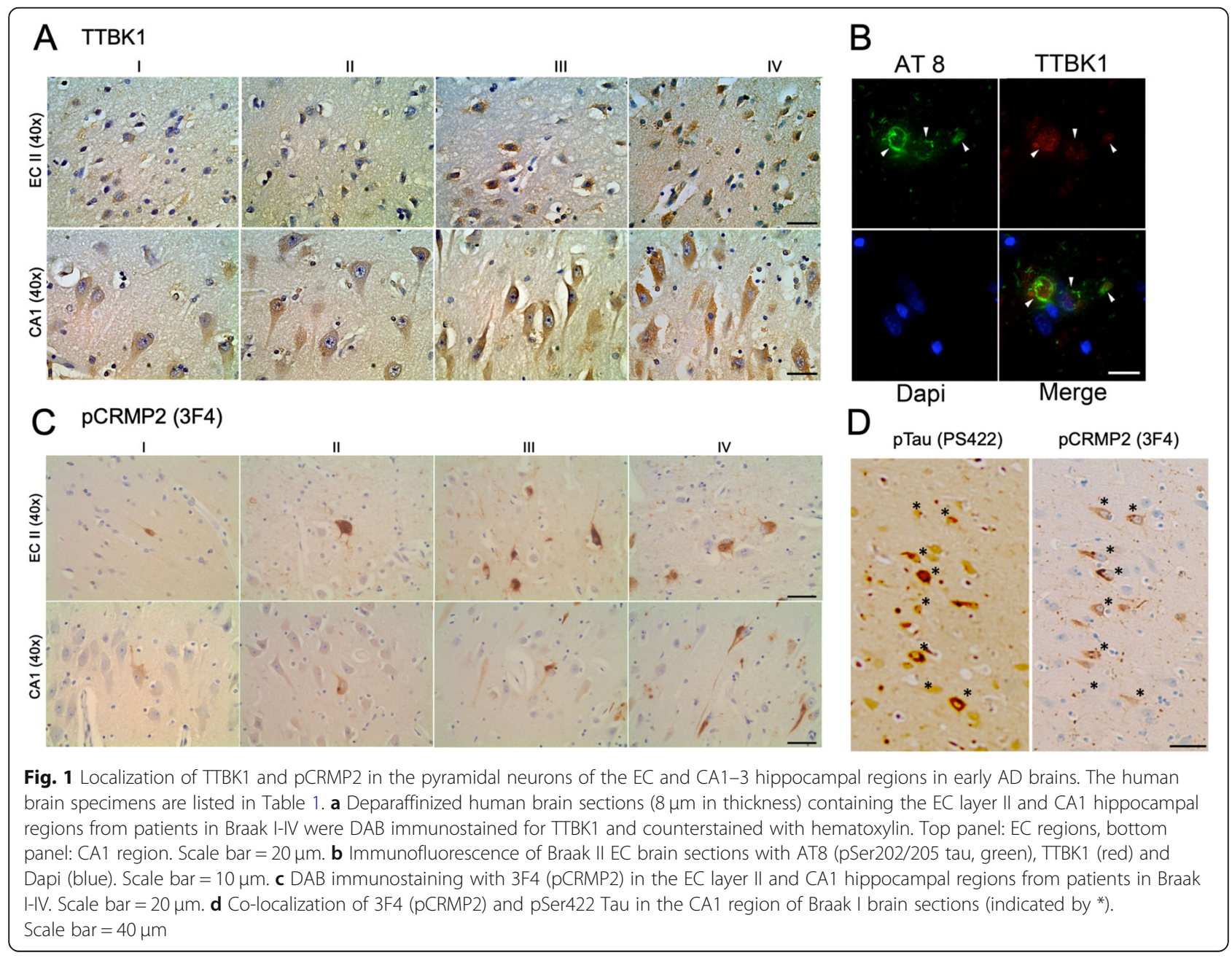


(pTau) in the frontal cortex of AD patients' brains (Fig. $1 \mathrm{~b})$, indicative of expression of TTBK1 in tau-bearing neurons in these regions.

Immunohistochemistry against 3F4 detecting phosphorylated CRMP2 (pCRMP2) at pT509/pS518/pS522 showed $\mathrm{pCRMP}^{+}$neurons as early as Braak I in the EC, subiculum and hippocampal CA1-3 fields (Fig. 1c and Table 1). A previous study reported the colocalization of TTBK1 with PS422 in pre-tangle neurons determined by immunohistochemistry with $\mathrm{AD}$ and non-symptomatic control brain samples [8], indicating a possible co-localization of TTBK1 and pCRMP2 in early tau pathology. The colocalization of p-tau and pCRMP2 has been reported in the brain tissue section of human AD, JNPL3 tau mouse, and 3xTg-AD rat models using a combination of AT8 and 3F4 (pCRMP2) [34], AT8 and pT509-CRMP2 or AT8 and pS522-pCRMP2 antibodies [35].We also observed colocalization of pCRMP2 and pS422 pTau in the CA1 field of Braak stage I specimen as determined by immunostaining of the adjacent sections of human brain tissue with 3F4 (pCRMP2) and PS422 (pTau, Fig. 1d). These data demonstrate that both $\mathrm{TTBK}^{+}$and $\mathrm{pCRMP}^{+}$are expressed in the EC and hippocampal neurons in the early Braak stage, and $\mathrm{pTau}^{+}$neurons show co-localization with TTBK1 or pCRMP2, suggesting the potential contribution of TTBK1 in pCRMP2 and pTau accumulation.

\section{Enhanced pCRMP2 accumulation by TTBK1 and APP expression in the mouse brain}

To assess whether increased expression of TTBK 1 and $A \beta$ accumulation directly induces pCRMP2 accumulation in vivo, we crossed Tg2576 mice expressing KM670/671NL Swedish mutation of human $\mathrm{APP}_{695}$ (APP mice) [15] and TTBK1 mice expressing human TTBK1 from bacterial artificial chromosome [7] to generate TTBK1, APP, APP/ TTBK1, and non-Tg littermates. These mice were tested at 10-11 months of age for immunofluorescence against pT514-CRMP2 in the EC and hippocampal regions. pT514CRMP2 was detected in the neurons of layer II/III of the EC of APP, TTBK1 and APP/TTBK1 mice but not in non-Tg mice (Fig. 2a, green and Additional file 1: Figure S2). APP/ TTBK1 mice show the most pronounced accumulation of pCRMP2 in the EC region, followed by TTBK1 and APP mice (Fig. 2b). These data support the previous in vivo demonstration of the age-dependent accumulation of pCRMP2 in the cortical region of Tg2576 [36]. Further, APP/TTBK1 mice also showed accumulation of pCRMP2 in the granular cell layer of the dentate gyrus (DG), suggesting that the coexistence of APP and TTBK1 expression in this region may enhance pCRMP2 accumulation (Fig. 2c-d, green and Additional file 1: Figure S2). The CA field did not show any pCRMP2 accumulation with these 3 mouse models. Taken together, we observed expression of pCRMP2 in the EC in aged TTBK1 and AD mouse models, which was exacerbated in APP/TTBK1 mice, whereas pCRMP2 accumulation in the DG was only observed in APP/TTBK1 mice.

\section{Axonal degeneration in the perforant path (PP) of TTBK1 and APP transgenic mice}

We have previously reported the specific accumulation of TTBK1 immunoreactivity in the PP of TTBK1 mice and the significant accumulation of phosphorylated neurofilament heavy chain in the EC layer II/III, which is indicative of axonal degeneration [7]. Accumulation of pT514CRMP2 is also indicative of the growth cone collapse in vitro $[13,16,37]$. In order to investigate the involvement of TTBK 1 and $A \beta$ in the axonal degeneration of the $\mathrm{PP}$, we tested the retrograde transport of DiI from the DG to the EC region through the PP. DiI was injected into the outer molecular layer of the DG of the hippocampal region of TTBK1, APP, APP/TTBK1 and non-Tg littermates, and the accumulation of DiI in the PP and EC regions was examined. Interestingly, we observed significant reduction of DiI signals in the PP and layer II/III region of the EC in TTBK1 mice and, to the lesser extent, APP mice compared to age-matched non-Tg littermates (Fig. 3a-b). The reduction of DiI signals was exacerbated in APP/TTBK1 mice compared to either TTBK1 or APP mice. Thus, we found that the intensity of DiI signal in the $\mathrm{EC}$ region was the highest in the non-Tg group, followed by APP, TTBK1 and APP/TTBK1 mice (Fig. 3c-d). Taken together, these data strongly suggest that TTBK1 and APP expression individually induces axonal degeneration of EC neurons in the PP, and that co-expression of TTBK1 and APP further enhances the axonal degeneration.

\section{$A \beta$ and TTBK1 reduce microtubule polymerization kinetics}

The collapsin signaling molecules, such as semaphorin or Eph family, mediate growth cone collapse through phosphorylation of CRMP2 [16]. CRMP2 is a cargo molecule that carries $\alpha / \beta$-tubulin hetero-dimers to the tip of microtubules via its binding to kinesins [38]. The collapsin-mediated phosphorylation of CRMP2 leads to the dissociation between itself and the tubulin dimers and kinesin, which triggers growth cone collapse and neurite retraction [39]. Given that A $\beta$ and TTBK1 may not only induce phosphorylation of tau but also potentially CRMP2, a key molecule to maintain the neurite integrity, we assessed if $A \beta$ and TTBK1 have effects on the dynamics of microtubule assembly, which may contribute to the neurite destabilization observed in TTBK1, APP, and APP/TTBK1 mice. We employed confocal microscopic real-time live imaging of microtubule polymerization by monitoring transiently expressed microtubule plus-endbinding (EB) 3-EGFP in SH-SY5Y human neuronal cells. EB3-GFP forms a homodimer at the plus-end tips of polymerizing microtubules, which enabled us to analyze the velocity of microtubule polymerization (Fig. 4a) [26]. 


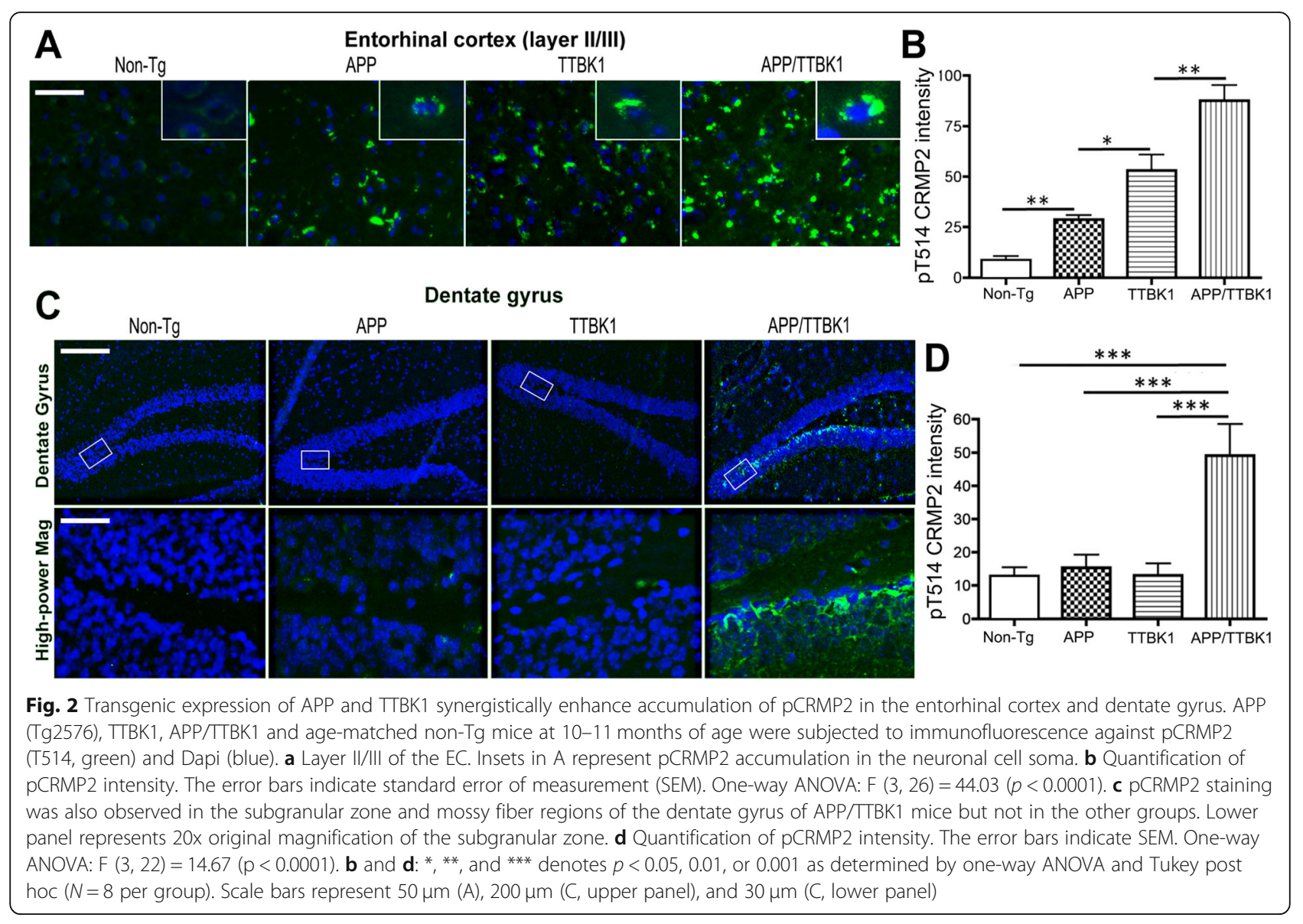

Treatment of EB3-GFP-expresssing SH-SY5Y cells with freshly prepared A $\beta 42$ oligomer or co-expression of TTBK1 significantly reduced the EB3-GFP comet velocity by 28 or $13 \%$ as compared to the mock-transfected control, respectively (Fig. 4b). These data demonstrate that A $\beta 42$ oligomer and TTBK1 can suppress the neurite elongation via suppression of the velocity of microtubule polymerization, which may lead to impaired neurite stability.

\section{TTBK1 expression and $A \beta$ stimulation induces CRMP2 phosphorylation at T514 in vitro}

We have previously shown that TTBK 1 activates $C d k 5$ via dissociation of Cdk5 from G-actin and recruitment of p35/ p25 to $\operatorname{Cdk} 5$ [7, 40]. Other evidence has shown that Cdk5 directly phosphorylates CRMP2 at Ser522, which is the priming step of the phosphorylation of CRMP2 at threonine 514 (T514) by GSK3 $\beta$ and this phosphorylation of CRMP2 at T514 is critical for the induction of neurite retraction [13]. We thus examined if TTBK1 expression facilitates phosphorylation of CRMP2 at T514 via Cdk5 activation in vitro. We found that transient expression of TTBK1 in human embryonic kidney 293 (HEK293) cells induced significant phosphorylation of CRMP2 at T514 (Fig. 5a, lane 1 and 2). This was abolished by Ser 522 to Ala mutation (S522A, lane 3 and 4) at the Cdk5 phosphorylation site, and partly abolished by Thr 555 to Ala mutation (T555A, lane 5 and 6) at the Rho kinase (RhoK) phosphorylation site [13, 37, 41]. These data suggest that TTBK1-induced T514 CRMP2 phosphorylation is dependent on both S522 phosphorylation by Cdk5 and T555 phosphorylation by RhoK.

In addition to the evidence of the relationship between TTBK1 and pCRMP2, previous reports suggest that $A \beta$ induces pCRMP2 in a RhoK-dependent manner [42]. Using human neuronal SH-SY5Y cells, we found that A 342 stimulation phosphorylates endogenous CRMP2 at T514 in a dose-dependent manner (Fig. 5c). Interestingly, we found that A 342 -induced phosphorylation of CRMP2 at T514 is dependent on TTBK1, since the siRNAmediated silencing of endogenous TTBK1 significantly reduces the pT514-CRMP2 level by $80 \%$ as compared to controls (Fig. 5d). Moreover, we observed synergistic enhancement of pT514-CRMP2 levels by A $\beta$ treatment and TTBK1 expression, which was significantly reduced by the co-expression of dominant-negative RhoK (DN-RhoK) (Fig. 5e). These data demonstrate that A 342 -induced pT514-CRMP2 is dependent on TTBK1, and that synergistic phosphorylation of pCRMP2 by A $\beta 42$ and TTBK1 is dependent on RhoK (Fig. 5b). 

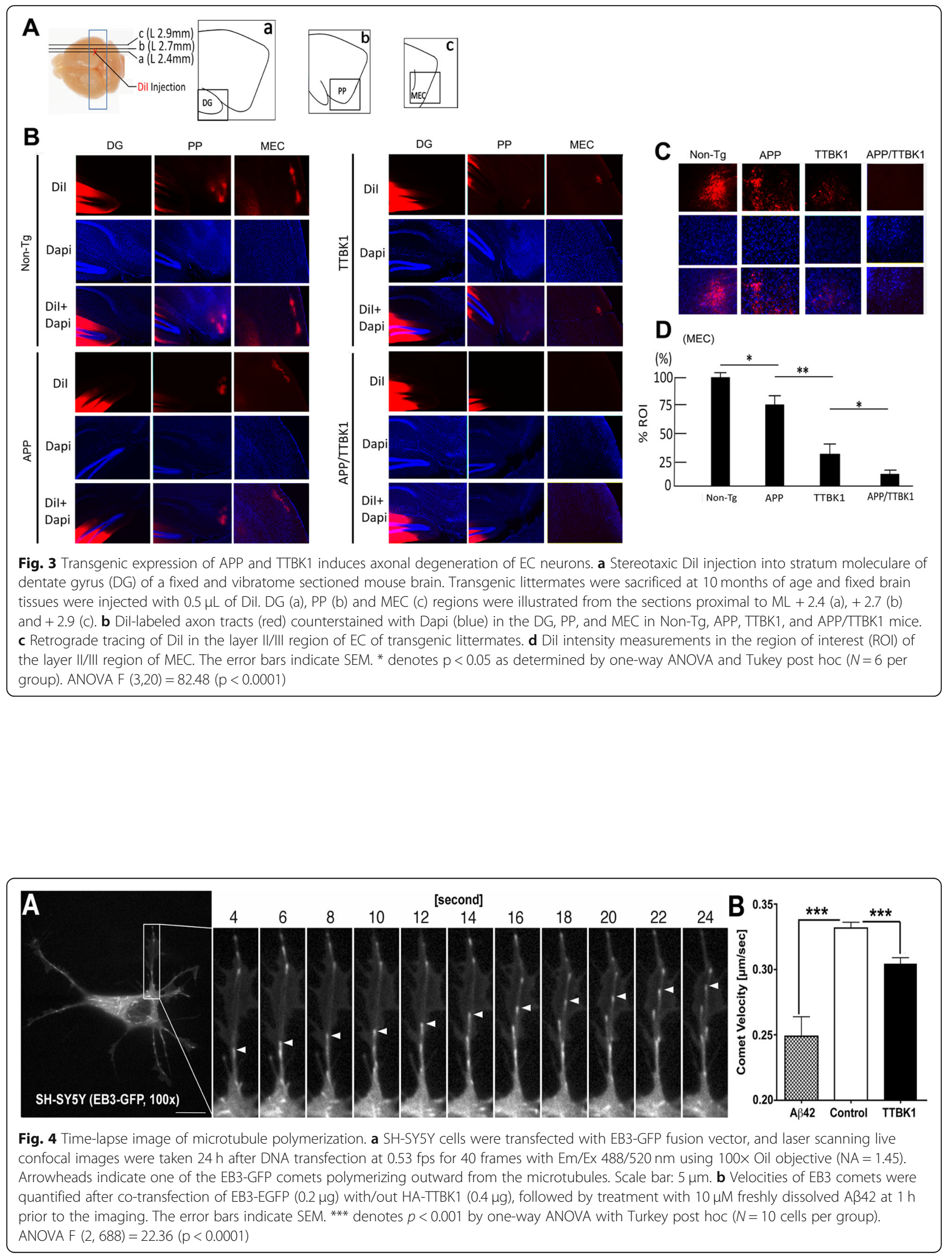


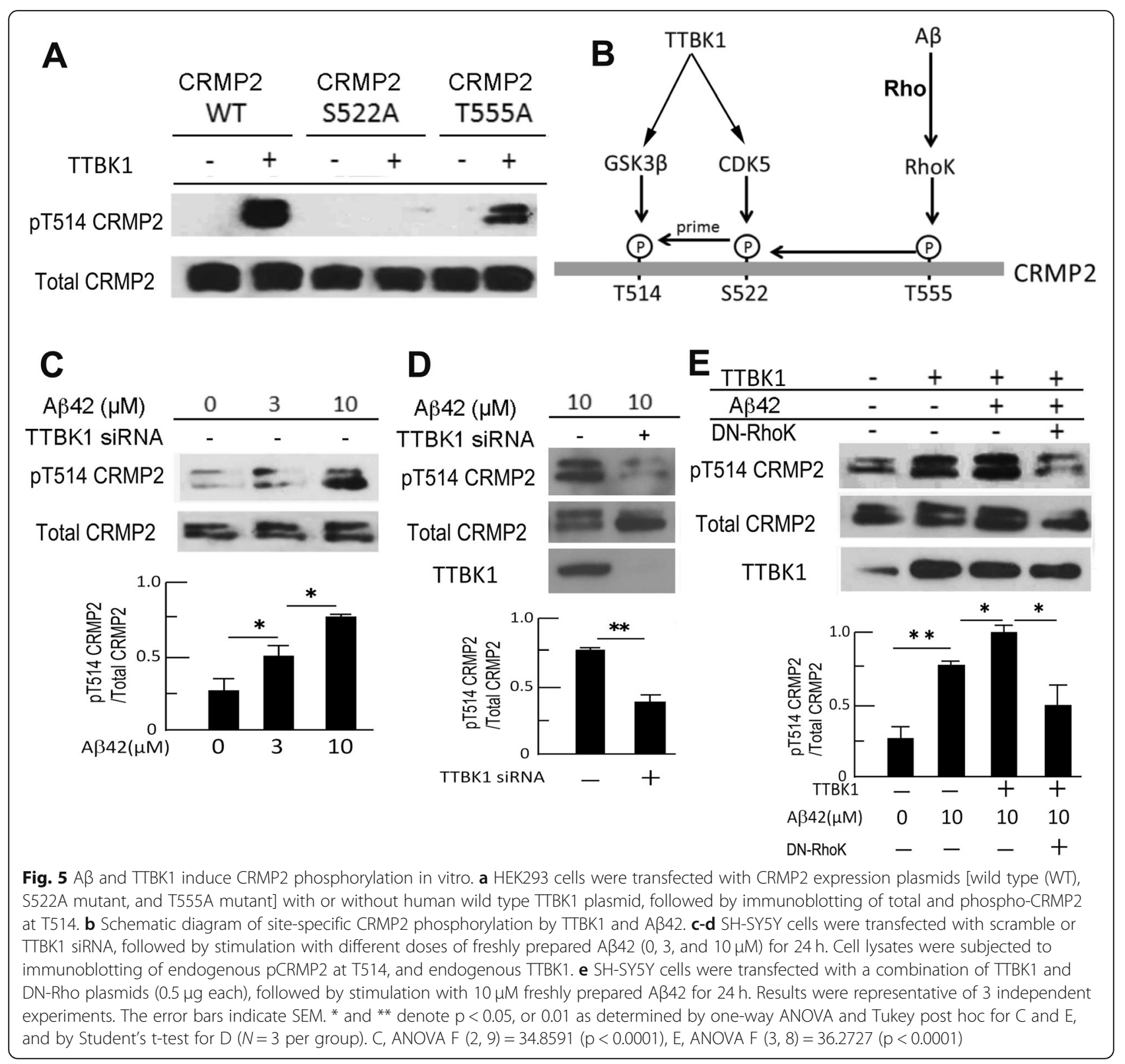

\section{TTBK1 induces neurite reduction in a rho-dependent} manner

Recent studies have shown that phosphorylation of CRMP2, an anterograde cargo transporter of tubulin dimer, is involved in the neurite degeneration pathology in multiple neurodegenerative diseases [43-45]. Nogo receptor 1, for example, induce axonal damage and demyelination in the experimental autoimmune encephalomyelitis mouse model through phosphorylation of CRMP2 by interfering axonal vesicle transport [43]. Indeed, several axon guidance molecules mediate their signaling through phosphorylation of CRMP2 [46]. Thus, based on our findings, we hypothesized that TTBK1 and $\mathrm{A} \beta$ suppress neurite elongation by CRMP2 phosphorylation, which is dependent on Rho- mediated RhoK activation. To test this hypothesis, primary cultured mouse cortical neurons were transiently transfected with TTBK1 and green fluorescent protein (GFP). Expression of TTBK1 dramatically shortened neurite length compared to controls (Fig. 6a-b). Since A $\beta$ and TTBK1induced T514 CRMP2 phosphorylation is dependent on its T555 phosphorylation by RhoK, and Rho activates RhoK to phosphorylate CRMP2 at T514 [16], we examined if the Rho/RhoK pathway is involved in TTBK1-mediated neurite reduction by co-transfection of dominant negative Rho (DN-Rho). The reduced neurite length was restored by cotransfection of DN-Rho with TTBK1, while single transfection of DN-Rho had no effect as compared to the GFP control group (Fig. 6b). Similarly, TTBK1 expression 

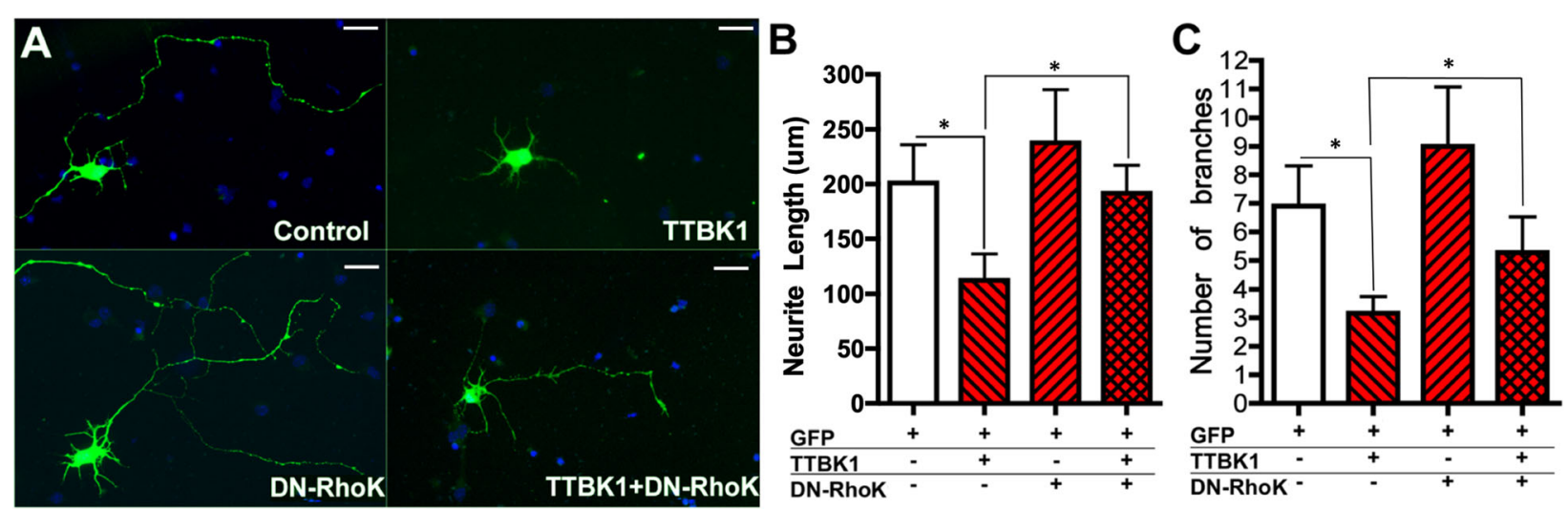

Fig. 6 TTBK1 suppresses axonal elongation in Rho-dependent manner. a Primary cultured mouse cortical neurons (green) were cultured on the PDL-coated coverslip in 24-well tissue culture plate, transfected with DNA plasmids expressing GFP, TTBK1, and/or DN-Rho (0.5 $\mu$ g) at 5 div and fixed at 8 div. Blue represents Dapi counterstain. $\mathbf{b}$-c Neurite length (b) and the number of branches from primary axons (c) in GFP ${ }^{+}$neurons were determined. Results were representative of 3 independent experiments. The error bars indicate SEM. * denotes $p<0.05$ as determined by one-way ANOVA with Tukey post hoc ( $N=10$ cells per group). ANOVA: $F(3,8)=36.273$ ( $p<0.0001)$. Scale bars represent $100 \mu m$

reduced the number of primary branches of dendrites, which is partially restored by the co-transfection of $\mathrm{DN}$ Rho (Fig. 6c). These data indicate that TTBK1 expression suppresses neuronal neurite extension and dendritic branching partially through the Rho/RhoK pathway.

\section{TTBK1 induces complex formation of pCRMP2 with pTau}

Since TTBK1 phosphorylates CRMP2 and tau proteins, and pCRMP2 is a component of neurofibrillary tangles in the $\mathrm{AD}$ brain [23], we hypothesized that TTBK1 expression or A $\beta$ treatment directly induces physical association of CRMP2 and tau protein in their phosphorylation-dependent manner. To assess this hypothesis, Myc-tagged CRMP2 were expressed with or without TTBK1 in SH-SY5Y cells stably expressing human full-length wild type tau protein [18], followed by treatment with freshly prepared $A \beta 42$. The cell lysate samples were immunoprecipitated for CRMP2 by anti-Myc antibody, and immunoblotted for pTau (AT8), total tau (Tau46), and non-phosphorylated tau (Tau-1). TTBK1 expression significantly induced CRMP2 binding to tau, which was enhanced by A $\beta 42$ treatment (Fig. 7a-b, top panels), while $A \beta 42$ treatment itself, conversely had no effect on the binding (Fig. 7a-b, top panels). The physical association of CRMP2 to tau appears to be dependent on tau phosphorylation, since no Tau-1 (specific to nonphosphorylated tau at Ser 195, Ser 198, Ser 199 and Ser 202 [27]) immunoreactivity was observed in CRMP2immunoprecipitated samples (Fig. 7a, top panel). A similar finding was also observed in the samples immunoprecipitated with pT514-CRMP2 antibody and immunoblotted for AT8, Tau46, and Tau-1 (Fig. 7a middle panel, 7B bottom panel). The immunoblot of the $5 \%$ of the input for the immunoprecipitation shows equal amount of total tau (T46) and CRMP2 expression, induction of $\mathrm{AT}^{+}$pTau by TTBK1 expression and its enhancement by A 342 stimulation (Fig. 7a, bottom panel). Tau-1 immunoreactivity, representing non-phosphorylated tau, is reduced by TTBK1 expression and A 342 treatment. These data demonstrate that TTBK1 expression is sufficient for CRMP2/ tau complex formation in their phosphorylation dependent manner, and $A \beta 42$ stimulation can augment the complex formation.

\section{pCRMP2 binds to pTau in the EC of TTBK1 and APP/ TTBK1 mice}

To determine whether TTBK1 induces pTau and pCRMP2 complex formation in vivo, we assessed accumulation of pTau in pCRMP2-positive neurons in the specific brain regions in TTBK1 and APP mouse models. Our attempt to detect pTau in the EC or hippocampal region by AT8 or PHF-1 staining in these mice was unsuccessful at this age. This suggests that the endogenous tau expression is insufficient for detecting the pTau/CRMP2 complex formation by immunofluorescence. Therefore, brain lysates from the EC and DG with TTBK1 and APP mouse models were immunoprecipitated for T514-phosphorylated CRMP2 and immunoblotted for tau (Fig. 8a-b). pCRMP2 forms a complex with pTau in the EC regions of TTBK1 and APP/TTBK1 mice, while this complex formation in the hippocampal region was only detected in APP/TTBK1 mice (Fig. 8a). The immunoreactivity of co-precipitated tau (AT8 or Tau46) was strongest in APP/TTBK1, followed by TTBK1, APP mice and non-Tg littermates in the EC (Fig. 8b), whereas it was only significant in the hippocampus with APP/TTBK1 mice (Fig. 8b). Taken together, these data demonstrate that TTBK1 but not APP transgene expression alone induce the complex formation of pTau and pCRMP2 in the EC, whereas co-expression of APP and TTBK1 transgene enhance the complex formation of pTau and pCRMP2 in both the EC and hippocampal regions. 


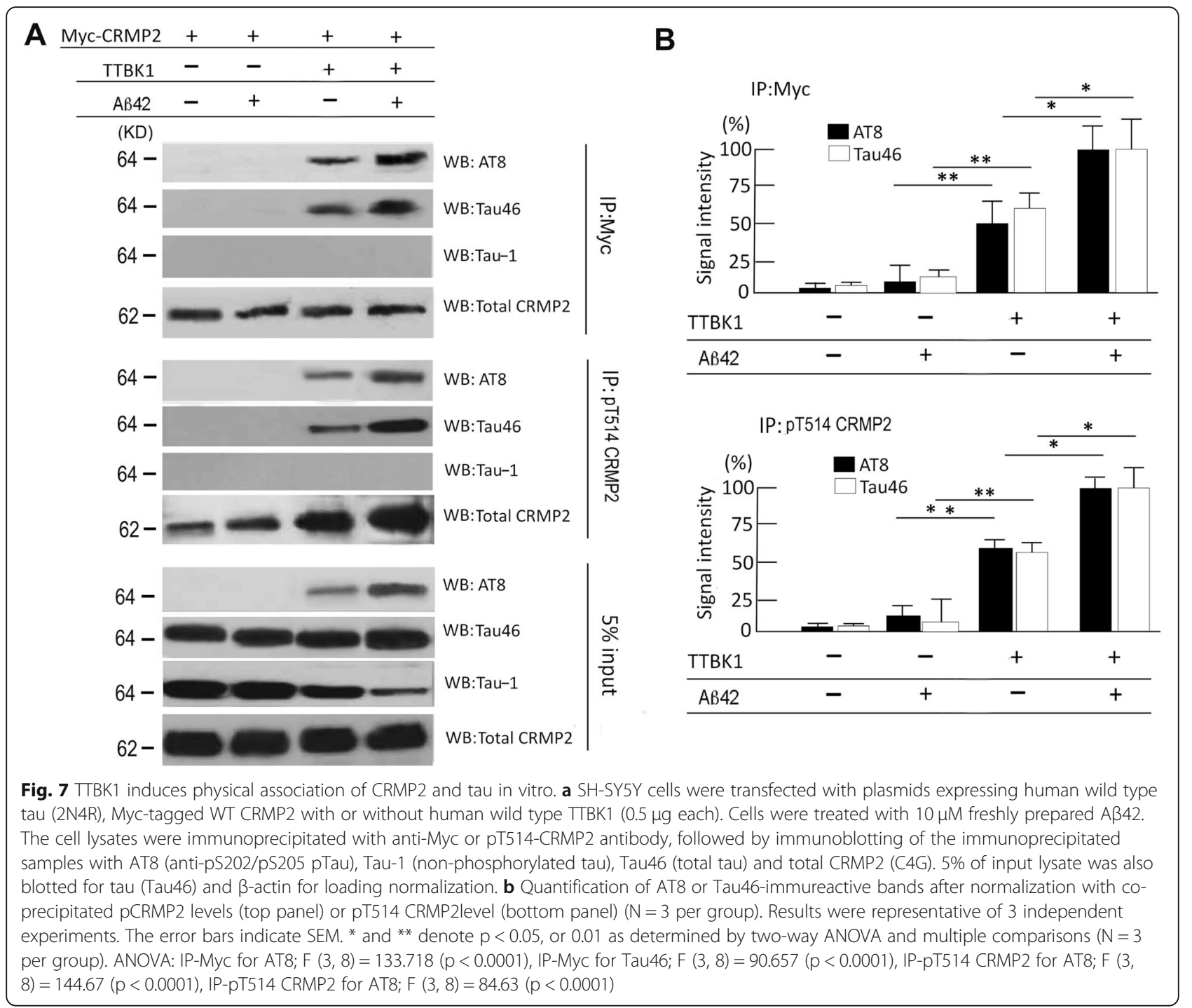

\section{Discussion}

In this study, we have demonstrated that 1) the expression of TTBK1 and accumulation of pCRMP2 is observed in the EC, subiculum, and CA1-3 pyramidal neurons of $\mathrm{AD}$ brains through the Braak stage I-IV for AD tau pathology, 2) TTBK1, APP and TTBK1/APP mice show somal accumulation of T514 phosphorylated CRMP2 and axonal degeneration in EC neurons, 3) TTBK1 and $A \beta$ reduces the velocity of microtubule extension, 4) TTBK1 expression suppresses neurite elongation and branching, 5) $\mathrm{A} \beta$ and TTBK1 induces phosphorylation of T514 CRMP2, which is dependent on its S522 and T555 phosphorylation and 6) TTBK1 induces phosphorylation of CRMP2 and tau, and their complex formation in vitro and in vivo, which was enhanced by $\mathrm{A} \beta$ treatment (in vitro) or accumulation (in vivo).
TTBK1 mice show significant axonal degeneration in the PP as determined by accumulation of phosphorylated neurofilament heavy chain in the EC region [7]. Phosphorylation of tau in the proline-rich regions (I151-L243) and C-terminal region (I371-L441), such as T181, S198, S199, S202, S205, T231, S396, S404, S422 causes detachment of tau from the microtubules and destabilizes cytoskeletal integrity, leading to neurite degeneration. Since TTBK1 can directly phosphorylate tau at Y197, S198, S199, S202 and S422 [6, 8, 47], as well as activate Cdk5 and GSK3 $\beta$, TTBK1 may contribute to neurite degeneration by phosphorylating tau protein. In this study, however, we have revealed a new pathological function of TTBK1 to phosphorylate CRMP2, which will also destabilize microtubule assembly.

We directly assessed the integrity of the PP via DiItracing from the DG to EC, which was reduced in TTBK1 mice and further compromised in APP/TTBK1 mice. 


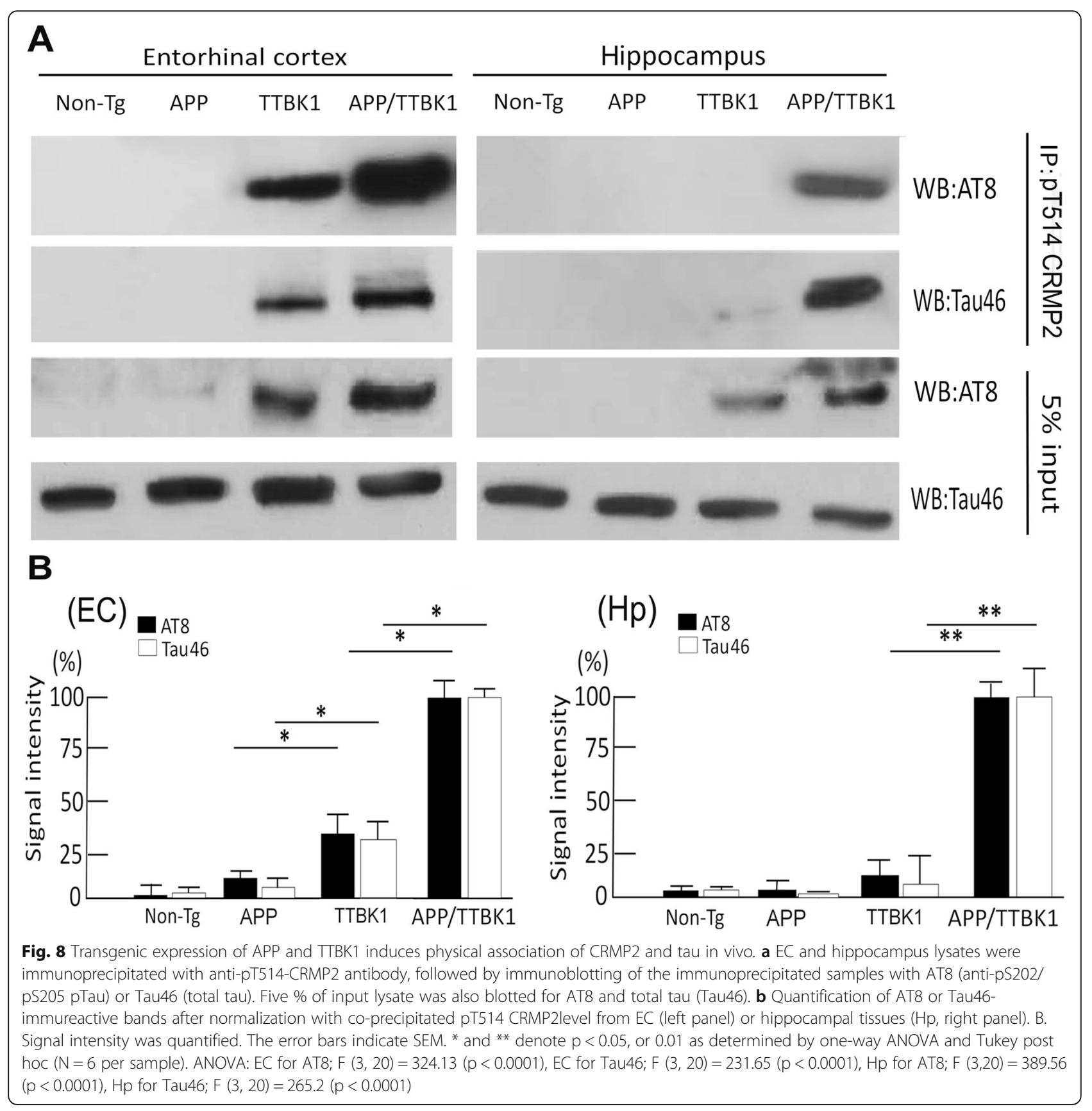

Accumulation of pT514-CRMP2 in the EC neurons was also found in APP, TTBK1 and APP/ TTBK1 mouse models, therefore we hypothesized that neurite degeneration facilitated by TTBK1 are mediated in part by PCRMP2. CRMP2 plays a physiological role on neurite elongation by transporting $\alpha / \beta$-tubulin heterodimers to the axonal terminal via kinesin-1-dependent anterograde transport [38, 48]. CRMP2 is also an essential molecule for regulating the axon elongation by axon guidance molecules (such as Semaphorin 3A) and $\mathrm{A} \beta[36,46]$, and its collapsing function is regulated by its site-specific phosphorylation at T555, S522 and finally T514 by RhoK, Cdk5 and GSK3 $\beta$, respectively [13, 16, 37].
Therefore, the lack of tubulin heterodimer supply to the plus-end of the microtubule terminal by pCRMP2 may initiate microtubule depolymerization, leading to the neurite degeneration (Fig. 9).

Interestingly, recent studies suggest involvement of pCRMP2 in axonal degeneration pathology in multiple sclerosis both in an animal model and in human brain tissue samples [44]. $\mathrm{pCRMP2}^{+}$axonal staining was found in the plaque core and peripheral white matter with acute and chronic-active multiple sclerosis patients. A similar result was also found in the spinal cord injury rat model and the experimental autoimmune encephalomyelitis mouse model. 


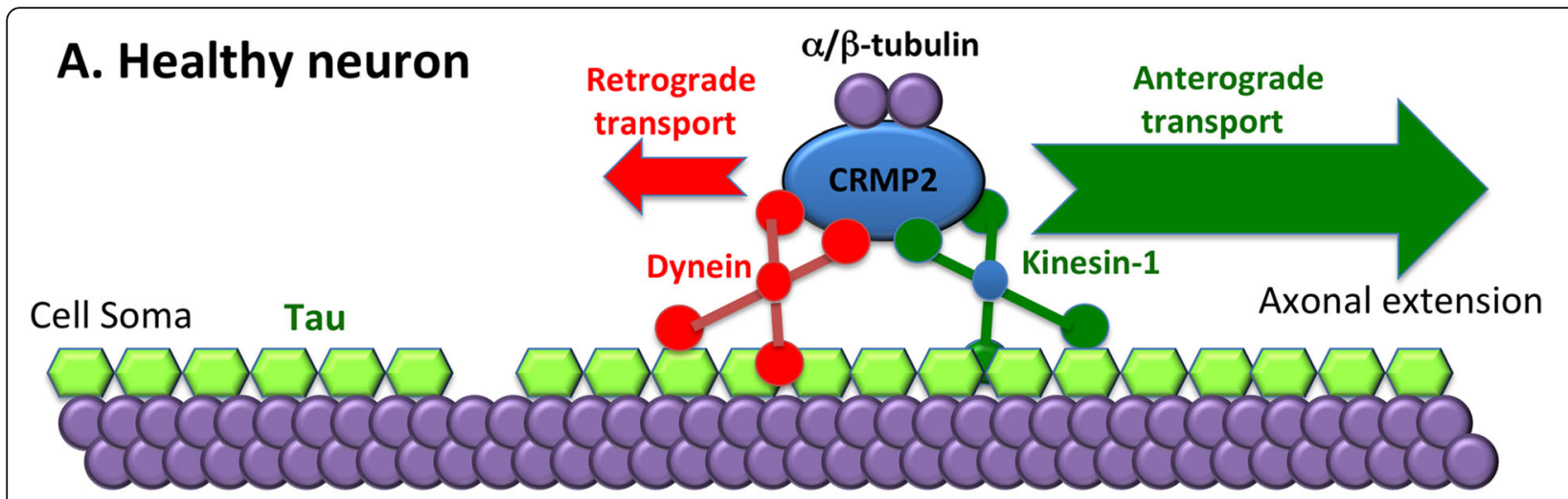

\section{B. Degenerating neuron}

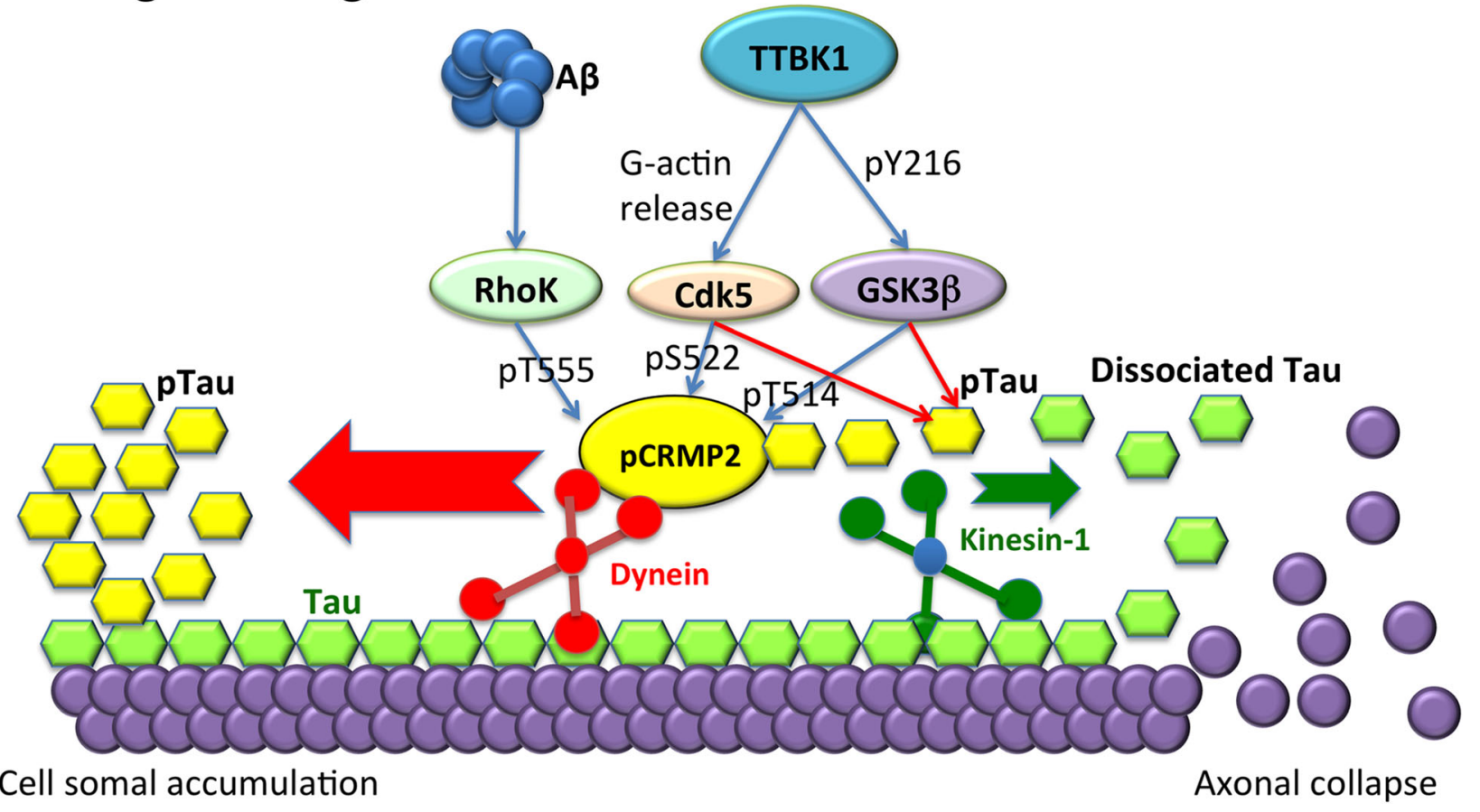

Fig. 9 Schematic diagram of A 3 and TTBK1-induced phosphorylation of CRMP2 and tau, neurite degeneration and their accumulation in neuronal cell soma. a In healthy neurons, kinesin-1-mediated anterograde transport is dominant (green arrow) over dynein-mediated retrograde transport (red arrow) for transporting $\alpha / \beta$-tubulin dimer for axonal extension. $\mathbf{b}$ Upon stimulation with $A \beta$ or activation of protein kinases by TTBK1, CRMP2 is phosphorylated by Cdk5, GSK3 $\beta$ and RhoK (pCRMP2, yellow), and dissociates from kinesin-1, leading to more retrogradedominant transport (red arrow) over their anterograde transport (green arrow). The loss of supply of a/ $\beta$-tubulin by CRMP2 to the microtubule tip leads to depolymerization of neurite terminal, inducing dissociation of tau (green). Dissociated tau is phosphorylated by tau kinases (pTau, yellow), which binds to PCRMP2 and concentrates in the cell soma via retrograde transport. The pCRMP2/pTau complex was found in EC neurons in TTBK1 mice. Accumulation of $A \beta$ may accelerate this process and promote $p C R M P 2$ accumulation in not only EC but also DG neurons in APP/TTBK1 mice

In this study, we identified a unique signaling pathway where TTBK1 induces CRMP2 phosphorylation at pT514 that is dependent on its phosphorylation at S522 and T555. Moreover, we also found that $A \beta$ induces pT514-CRMP2 in a TTBK1 and RhoK-dependent manner. We showed that both $\mathrm{A} \beta$ and TTBK1 suppress microtubule polymerization as determined by EB3-GFP live imaging and reduced neurite elongation speed in TTBK1-transfected mouse cortical neurons in a Rho-dependent manner. Taken together, these data suggest that $A \beta$ induces Rho activation and pT514-CRMP2 leading to neurite degeneration in a TTBK1-dependent manner.

Mounting evidence has shown that neurons that undergo die back neurons seen in neurodegenerative diseases possess microtubule-associated molecules in the cell soma such as TTBK1 or pCRMP2 as well as phosphorylated tau protein. Recent work has shown that TTBK1 is co-localized with 
pS422 ${ }^{+}$pTau in neuronal cell soma containing pre-tangles but not in neuropil threads or neurofibrillary tangles [8]. Since TTBK1 can directly phosphorylate tau at S422, this data suggest its role in $\mathrm{pS}_{2} 22^{+}$pTau accumulation in pre-tangle ${ }^{+}$ neurons $[6,49]$. In this study, we confirmed that TTBK1 is co-localized with $\mathrm{AT}^{+}$pTau in neurons, supporting the previous finding of our data showing that TTBK1/P301L tau bigenic mice exhibited enhanced $\mathrm{AT}^{+}$tau oligomer formation compared to P301L tau mice [5]. pCRMP2 was identified in the neurofibrillary tangles isolated from human $\mathrm{AD}$ brains [23]. We have shown for the first time that PCRMP2 is colocalized in phospho-Ser 422 positive pyramidal CA1 neurons with Braak Stage 1 human brain tissue. A previous study and ours showed that pCRMP2 binds to pTau [34].Moreover, pCRMP2 and p-tau complex formation was induced by TTBK 1 and exacerbated by $A \beta$ in vitro and in vivo. Therefore, these findings suggest that together with TTBK1, pCRMP2 may be involved in the early phase of tau phosphorylation and pre-tangle formation in AD pathology.

In conclusion, our study has integrated the biological function of CRMP2, region-specific expression and molecular function of TTBK1 and A $\beta$ accumulation as novel pathogenic mechanism of neurite degenerations and tau accumulation in the affected brain regions of $\mathrm{AD}$, most importantly in the EC layer II. Since individuals in Braak stage I or II are prodromal AD and mostly cognitively normal, early intervention of neurite degeneration by TTBK1-specific inhibitors may potentially serve as a preventive therapy for AD. Unlike RhoK, GSK3 $\beta$, or Cdk5, TTBK1 is specifically expressed in neurons, thus it is an attractive therapeutic target with less off-target potential.

\section{Supplementary information}

Supplementary information accompanies this paper at https://doi.org/10. 1186/s40478-020-0890-4

Additional file 1: Figure S1. Representative conversion of CMYK format and extraction of $Y$ channel (right) for DAB intensity measurement. Figure S2. Split channel images of pCRMP2 (green in bottom panels of $A$ and $B$ ) and Dapi (blue in bottom panels of $A$ and $B$ ) as shown in Fig. 2a and c. Scale bars $=50$ (A) and $200 \mu \mathrm{m}(C)$.

\section{Acknowledgements}

We would like to thank Drs. H. Asai and other members of Laboratory of Molecular NeuroTherapeutics for supporting this research, Dr. Y. Ihara (Doshisha University) for his suggestion of the TTBK1 CRMP2 connection, Dr. Y. Goshima (Yokohama City University) for the CRMP2 plasmids, Dr. K. Ashe (University of Minnesota) for Tg2676 mice, Dr. S. Popov (University of Illinois at Chicago) for the EB1- and EB3-GFP plasmids and Ms. S. Walsh (University of Nebraska Medical Center) for assistance in live confocal microscopic imaging and analysis.

\section{Authors' contributions}

SI carried out the immunohistochemistry-related experiments. KLID carried out the tissue culture-related experiments and image analyses. LK carried out the quantitative analysis of immunohistochemistry and participated in tissue culure and molecular biology-related experiments. TW and KK participated in construction and validation of plasmid vectors by transient expression and biochemistry, and the experimental design using the vectors. SI and TI participated in the design of the study, performed the statistical analysis and wrote the manuscript. All authors read, edited and approved the final manuscript.

\section{Funding}

This work was funded in part by NIH RF1AG054199 (TI), NIH R01AG054672 (TI), NIH R56AG057469 (TI), Cure Alzheimer's Fund (TI), BrightFocus Foundation (A2016551S, TI), Coins for Alzheimer's Research Trust (TI), CurePSP (TI), BU ADC P30AG013846 (SI).

Availability of data and materials

The authors declare the data and material availability in this manuscript

\section{Competing interests}

The authors declare that they have no competing interests.

\section{Author details}

'Departments of Pharmacology and Experimental Therapeutics, Boston University School of Medicine, Boston, MA, USA. ${ }^{2}$ Department of Cell Pharmacology, Graduate School of Medicine, Nagoya University School of Medicine, Aichi, Japan. ${ }^{3}$ Institute of Comprehensive Medical Science, Fujita Health University, Toyoake, Aichi, Japan. ${ }^{4}$ Department of Neurology, Alzheimer's Disease Center, Boston University School of Medicine, Boston, MA, USA. ${ }^{5}$ Center for Systems Neuroscience, Boston University, Boston, MA, USA.

Received: 25 November 2019 Accepted: 30 January 2020

Published online: 04 February 2020

\section{References}

1. Kalus P, Slotboom J, Gallinat J, Mahlberg R, Cattapan-Ludewig K, Wiest R, Nyffeler T, Buri C, Federspiel A, Kunz D et al (2006) Examining the gateway to the limbic system with diffusion tensor imaging: the perforant pathway in dementia. Neuroimage 30:713-720. https://doi.org/10.1016/j.neuroimage. 2005.10.035

2. Stoub TR, Bulgakova M, Leurgans S, Bennett DA, Fleischman D, Turner DA, deToledo-Morrell L (2005) MRI predictors of risk of incident Alzheimer disease: a longitudinal study. Neurology 64:1520-1524. https://doi.org/10. 1212/01.WNL.0000160089.43264.1A

3. Witter MP (2007) The perforant path: projections from the entorhinal cortex to the dentate gyrus. Prog Brain Res 163:43-61. https://doi.org/10.1016/ S0079-6123(07)63003-9

4. Suh J, Rivest AJ, Nakashiba T, Tominaga T, Tonegawa S (2011) Entorhinal cortex layer III input to the hippocampus is crucial for temporal association memory. Science 334:1415-1420. https://doi.org/10.1126/science.1210125

5. Xu J, Sato S, Okuyama S, Swan RJ, Jacobsen MT, Strunk E, Ikezu T (2010) Tau-tubulin kinase 1 enhances prefibrillar tau aggregation and motor neuron degeneration in P301L FTDP-17 tau-mutant mice. FASEB J 24:29042915. https://doi.org/10.1096/fj.09-150144 fj.09-150144 [pii]

6. Sato S, Cerny RL, Buescher JL, Ikezu T (2006) Tau-tubulin kinase 1 (TTBK1), a neuron-specific tau kinase candidate, is involved in tau phosphorylation and aggregation. J Neurochem 98: 1573-1584 Doi JNC4059 [pii]. https://doi.org/ 10.1111/j.1471-4159.2006.04059.x

7. Sato S, Xu J, Okuyama S, Martinez LB, Walsh SM, Jacobsen MT, Swan RJ, Schlautman JD, Ciborowski P, Ikezu T (2008) Spatial learning impairment, enhanced CDK5/p35 activity, and downregulation of NMDA receptor expression in transgenic mice expressing tau-tubulin kinase 1. J Neurosci 28:14511-14521. https:/doi.org/10.1523/JNEUROSCl.3417-08.2008 28/53/14511 [pii]

8. Lund H, Cowburn RF, Gustafsson E, Stromberg K, Svensson A, Dahllund L, Malinowsky D, Sunnemark D (2013) Tau-tubulin kinase 1 expression, phosphorylation and co-localization with phospho-Ser422 tau in the Alzheimer's disease brain. Brain Pathol 23:378-389. https://doi.org/10.1111/bpa.12001

9. Vazquez-Higuera JL, Martinez-Garcia A, Sanchez-Juan P, RodriguezRodriguez E, Mateo I, Pozueta A, Frank A, Valdivieso F, Berciano J, Bullido MJ et al (2011) Genetic variations in tau-tubulin kinase-1 are linked to Alzheimer's disease in a Spanish case-control cohort. Neurobiol Aging 32: 550. https://doi.org/10.1016/j.neurobiolaging.2009.12.021 S01974580(10)00006-0 [pii], e555-559

10. Yu NN, Yu JT, Xiao JT, Zhang HW, Lu RC, Jiang H, Xing ZH, Tan L (2011) Tautubulin kinase-1 gene variants are associated with Alzheimer's disease in 
Han Chinese. Neurosci Lett 491:83-86. https://doi.org/10.1016/j.neulet.2011. 01.011 S0304-3940(11)00015-2 [pii]

11. Asai H, Ikezu S, Woodbury ME, Yonemoto GM, Cui L, Ikezu T (2014) Accelerated neurodegeneration and neuroinflammation in transgenic mice expressing P301L tau mutant and tau-tubulin kinase 1. Am J Pathol 184: 808-818. https://doi.org/10.1016/.ajpath.2013.11.026

12. Morfini GA, Burns M, Binder LI, Kanaan NM, LaPointe N, Bosco DA, Brown RH, Jr., Brown H, Tiwari A, Hayward Let al (2009) Axonal transport defects in neurodegenerative diseases. J Neurosci 29: 12776-12786 Doi https://doi. org/10.1523/JNEUROSCI.3463-09.2009

13. Yoshimura T, Kawano Y, Arimura N, Kawabata S, Kikuchi A, Kaibuchi K (2005) GSK-3beta regulates phosphorylation of CRMP-2 and neuronal polarity. Cell 120:137-149

14. Yoshida H, Watanabe A, Ihara Y (1998) Collapsin response mediator protein2 is associated with neurofibrillary tangles in Alzheimer's disease. J Biol Chem 273:9761-9768

15. Hsiao K, Chapman P, Nilsen S, Eckman C, Harigaya Y, Younkin S, Yang F, Cole G (1996) Correlative memory deficits, Abeta elevation, and amyloid plaques in transgenic mice. Science 274:99-102

16. Arimura N, Inagaki N, Chihara K, Menager C, Nakamura N, Amano M, Iwamatsu A, Goshima Y, Kaibuchi K (2000) Phosphorylation of collapsin response mediator protein-2 by rho-kinase. Evidence for two separate signaling pathways for growth cone collapse. J Biol Chem 275:23973-23980. https://doi.org/10.1074/jbc.M001032200

17. Oshiro N, Fukata Y, Kaibuchi K (1998) Phosphorylation of moesin by rhoassociated kinase (rho-kinase) plays a crucial role in the formation of microvilli-like structures. J Biol Chem 273:34663-34666

18. Ferrari A, Hoerndli F, Baechi T, Nitsch RM, Gotz J (2003) Beta-amyloid induces paired helical filament-like tau filaments in tissue culture. J Biol Chem 278:40162-40168

19. Jun G, Asai H, Zeldich E, Drapeau E, Chen C, Chung J, Park JH, Kim S, Haroutunian V, Foroud T et al (2014) PLXNA4 is associated with Alzheimer disease and modulates tau phosphorylation. Ann Neurol 76:379-392. https://doi.org/10.1002/ana.24219

20. Kiyota T, Ingraham KL, Jacobsen MT, Xiong H, Ikezu T (2011) FGF2 gene transfer restores hippocampal functions in mouse models of Alzheimer's disease and has therapeutic implications for neurocognitive disorders. Proc Natl Acad Sci U S A 108:E1339-E1348. https://doi.org/10.1073/pnas.1102349108

21. Tokuraku K, Marquardt M, Ikezu T (2009) Real-time imaging and quantification of amyloid-beta peptide aggregates by novel quantum-dot nanoprobes. PLoS One 4:e8492. https://doi.org/10.1371/journal.pone.0008492

22. Meijering E, Jacob M, Sarria JC, Steiner P, Hirling H, Unser M (2004) Design and validation of a tool for neurite tracing and analysis in fluorescence microscopy images. Cytometry A 58:167-176. https://doi.org/10.1002/cyto.a.20022

23. Gu Y, Hamajima N, Ihara Y (2000) Neurofibrillary tangle-associated collapsin response mediator protein-2 (CRMP-2) is highly phosphorylated on Thr-509, Ser-518, and Ser-522. Biochemistry 39:4267-4275

24. Jamsa A, Hasslund K, Cowburn RF, Backstrom A, Vasange M (2004) The retinoic acid and brain-derived neurotrophic factor differentiated SH-SY5Y cell line as a model for Alzheimer's disease-like tau phosphorylation. Biochem Biophys Res Commun 319:993-1000

25. Martinez LB, Walsh SM, Jacobsen MT, Sato S, Wiederin J, Ciborowski P, Ikezu T (2009) Calpain and proteasomal regulation of antiretroviral zinc finger protein OTK18 in human macrophages: visualization in live cells by intramolecular FRET. J Neurolmmune Pharmacol 4:116-128. https://doi.org/ 10.1007/s11481-008-9140-4

26. Stepanova T, Slemmer J, Hoogenraad CC, Lansbergen G, Dortland B, De Zeeuw Cl, Grosveld F, van Cappellen G, Akhmanova A, Galjart N (2003) Visualization of microtubule growth in cultured neurons via the use of EB3-GFP (end-binding protein 3-green fluorescent protein). J Neurosci 23:2655-2664

27. Tatebayashi Y, Miyasaka T, Chui DH, Akagi T, Mishima K, Iwasaki K, Fujiwara M, Tanemura K, Murayama M, Ishiguro K et al (2002) Tau filament formation and associative memory deficit in aged mice expressing mutant (R406W) human tau. Proc Natl Acad Sci U S A 99:13896-13901

28. Montine TJ, Phelps CH, Beach TG, Bigio EH, Cairns NJ, Dickson DW, Duyckaerts C, Frosch MP, Masliah E, Mirra SS et al (2012) National Institute on Aging-Alzheimer's Association guidelines for the neuropathologic assessment of Alzheimer's disease: a practical approach. Acta Neuropathol 123:1-11. https://doi.org/10.1007/s00401-011-0910-3

29. Newell KL, Hyman BT, Growdon JH, Hedley-Whyte ET (1999) Application of the National Institute on Aging (NIA)-Reagan institute criteria for the neuropathological diagnosis of Alzheimer disease. J Neuropathol Exp Neurol 58:1147-1155

30. Braak H, Braak E (1991) Neuropathological stageing of Alzheimer-related changes. Acta Neuropathol 82:239-259

31. Braak H, Braak E (1995) Staging of Alzheimer's disease-related neurofibrillary changes. Neurobiol Aging 16:271-278 discussion 278-284

32. Mirra SS, Heyman A, McKeel D, Sumi SM, Crain BJ, Brownlee LM, Vogel FS, Hughes JP, van Belle G, Berg L (1991) The consortium to establish a registry for Alzheimer's disease (CERAD). Part II Standardization of the neuropathologic assessment of Alzheimer's disease. Neurology 41:479-486

33. Pham NA, Morrison A, Schwock J, Aviel-Ronen S, lakovlev V, Tsao MS, Ho J, Hedley DW (2007) Quantitative image analysis of immunohistochemical stains using a CMYK color model. Diagn Pathol 2:8. https//doi.org/10.1186/1746-1596-2-8

34. Takata K, Kitamura Y, Nakata Y, Matsuoka Y, Tomimoto H, Taniguchi T, Shimohama S (2009) Involvement of WAVE accumulation in Abeta/APP pathology-dependent tangle modification in Alzheimer's disease. Am J Pathol 175:17-24. https://doi.org/10.2353/ajpath.2009.080908

35. Watamura N, Toba J, Yoshii A, Nikkuni M, Ohshima T (2016) Colocalization of phosphorylated forms of WAVE1, CRMP2, and tau in Alzheimer's disease model mice: involvement of $\mathrm{Cdk} 5$ phosphorylation and the effect of ATRA treatment. J Neurosci Res 94:15-26. https://doi.org/10.1002/jnr.23674

36. Petratos $\mathrm{S}, \mathrm{Li} \mathrm{QX}$, George AJ, Hou X, Kerr ML, Unabia SE, Hatzinisiriou I, Maksel D, Aguilar Ml, Small DH (2008) The beta-amyloid protein of Alzheimer's disease increases neuronal CRMP-2 phosphorylation by a rhoGTP mechanism. Brain 131:90-108. https://doi.org/10.1093/brain/awm260

37. Arimura N, Menager C, Kawano Y, Yoshimura T, Kawabata S, Hattori A, Fukata Y, Amano M, Goshima Y, Inagaki M et al (2005) Phosphorylation by rho kinase regulates CRMP-2 activity in growth cones. Mol Cell Biol 25: 9973-9984. https://doi.org/10.1128/MCB.25.22.9973-9984.2005

38. Fukata Y, Itoh TJ, Kimura T, Menager C, Nishimura T, Shiromizu T, Watanabe $\mathrm{H}$, Inagaki N, Iwamatsu A, Hotani $\mathrm{H}$ et al (2002) CRMP-2 binds to tubulin heterodimers to promote microtubule assembly. Nat Cell Biol 4:583-591. https://doi.org/10.1038/ncb825

39. Arimura N, Kimura T, Nakamuta S, Taya S, Funahashi Y, Hattori A, Shimada A Menager C, Kawabata S, Fujii K et al (2009) Anterograde transport of TrkB in axons is mediated by direct interaction with Slp1 and Rab27. Dev Cell 16: 675-686. https://doi.org/10.1016/j.devcel.2009.03.005

40. Xu J, Tsutsumi K, Tokuraku K, Estes KA, Hisanaga SI, Ikezu T (2010) Actin interaction and regulation of cyclin-dependent kinase 5/p35 complex activity. J Neurochem 116:192-204. https://doi.org/10.1111/j.1471-4159.2010. 06824.x JNC6824 [pii]

41. Amano M, Chihara K, Nakamura N, Kaneko T, Matsuura Y, Kaibuchi K (1999) The $\mathrm{COOH}$ terminus of rho-kinase negatively regulates rho-kinase activity. J Biol Chem 274:32418-32424

42. Isono T, Yamashita N, Obara M, Araki T, Nakamura F, Kamiya Y, Alkam T, Nitta A, Nabeshima T, Mikoshiba K et al (2013) Amyloid-beta(2)(5)(-)(3)(5) induces impairment of cognitive function and long-term potentiation through phosphorylation of collapsin response mediator protein 2. Neurosci Res 77:180-185. https://doi.org/10.1016/j.neures.2013.08.005

43. Lee JY, Kim MJ, Thomas S, Oorschot V, Ramm G, Aui PM, Sekine Y, Deliyanti D, Wilkinson-Berka J, Niego B et al (2019) Limiting neuronal Nogo receptor 1 signaling during experimental autoimmune encephalomyelitis preserves axonal transport and abrogates inflammatory demyelination. J Neurosci 39: 5562-5580. https://doi.org/10.1523/JNEUROSCl.1760-18.2019

44. Petratos S, Ozturk E, Azari MF, Kenny R, Lee JY, Magee KA, Harvey AR, McDonald C, Taghian K, Moussa L et al (2012) Limiting multiple sclerosis related axonopathy by blocking Nogo receptor and CRMP-2 phosphorylation. Brain 135:1794-1818. https://doi.org/10.1093/brain/aws100

45. Wang Y, Yin H, Li J, Zhang Y, Han B, Zeng Z, Qiao N, Cui X, Lou J, Li J (2013) Amelioration of beta-amyloid-induced cognitive dysfunction and hippocampal axon degeneration by curcumin is associated with suppression of CRMP-2 hyperphosphorylation. Neurosci Lett 557(Pt B):112117. https://doi.org/10.1016/j.neulet.2013.10.024

46. Liu BP, Strittmatter SM (2001) Semaphorin-mediated axonal guidance via rho-related G proteins. Curr Opin Cell Biol 13:619-626

47. Cavallini A, Brewerton S, Bell A, Sargent S, Glover S, Hardy C, Moore R, Calley J, Ramachandran D, Poidinger M et al (2013) An unbiased approach to identifying tau kinases that phosphorylate tau at sites associated with Alzheimer disease. J Biol Chem 288:23331-23347. https:/doi.org/10.1074/jbc.M113.463984

48. Kawano Y, Yoshimura T, Tsuboi D, Kawabata S, Kaneko-Kawano T, Shirataki H, Takenawa T, Kaibuchi K (2005) CRMP-2 is involved in kinesin-1-dependent 
transport of the Sra-1/WAVE1 complex and axon formation. Mol Cell Biol 25: 9920-9935. https://doi.org/10.1128/MCB.25.22.9920-9935.2005

49. Ikezu S, Ikezu T (2014) Tau-tubulin kinase. Front Mol Neurosci 7:33. https:// doi.org/10.3389/fnmol.2014.00033

\section{Publisher's Note}

Springer Nature remains neutral with regard to jurisdictional claims in published maps and institutional affiliations.

Ready to submit your research? Choose BMC and benefit from:

- fast, convenient online submission

- thorough peer review by experienced researchers in your field

- rapid publication on acceptance

- support for research data, including large and complex data types

- gold Open Access which fosters wider collaboration and increased citations

- maximum visibility for your research: over $100 \mathrm{M}$ website views per year

At BMC, research is always in progress.

Learn more biomedcentral.com/submissions 